\title{
UM ESTUDO DE CASO SOBRE A PEDAGOGIA A DISTÂNCIA NA UNIGRAN E PRESENCIAL NA UEG EM CAMPOS BELOS DE GOIAS: A PERCEPÇÃO DOS ACADÊMICOS
}

\author{
Maike Soares de SOUZA ${ }^{\mathbf{1}}$ \\ Universidade Estadual de Goiás-UEG
}

Resumo: Este artigo concentra-se na formação inicial do curso de pedagogia, nas modalidades presencial e a distância, como objetivo de analisar as peculiaridades formativas presentes nos diferentes contextos em que se prepara profissionalmente o professor para a educação infantil. Destarte, é realizada uma pesquisa de campo na UEG e UNIGRAN, em Campos Belos de Goiás, com acadêmicos do curso de Pedagogia, a qual se utilizou do instrumento questionário, para a coleta de dados no primeiro citado, e entrevista, no segundo. Em suma, elucida-se o cotidiano de uma formação profissional, além dos anseios por avanços e diversos fatores específicos, delatando mazelas e impasses, constatando a necessidade de transformações e uma urgente ressignificação das modalidades em que se oferta a pedagogia, assim como o curso em questão.

Palavras-chave: Educação Infantil. Pedagogia. Formação. Presencial. EAD.
Abstract: The article concentrates on the initial formation in the pedagogy course in the face and distance modalities. The objective is to analyze the formative peculiarities present in the different contexts in which the teacher is prepared professionally for the infantile education. Thus, field research is carried out at the UEG and UNIGRAN in Campos Belos de Goiás, with academics from the Pedagogy course, since the questionnaire was used for data collection, in the first one, and interview to the second. In short, the everyday life of a professional formation, in addition to the yearnings for progress and several specific factors, revealing problems and impasses, noting the need for transformations, and an urgent resignification of the modalities offered by pedagogy, as well as the course in question. Keywords: Infant Education. Pedagogy.

Formation. Presential. EAD.

\footnotetext{
${ }^{1}$ Graduação em Pedagogia-UEG e Especialização em Arte/Educação Intermidiática Digital pela UFG (2019) E-mail: maikeufg@gmail.com.
} 


\section{Introdução}

As constantes discussões acerca da qualidade e formação docente ganham grandes proporções na atual conjuntura, sendo então o estopim para investigar o cenário, no qual se modula a preparação de professores para educação infantil, percebendo que muitas são as ambiguidades presentes na licenciatura em Pedagogia, bem como, muitas são as propostas somadas para sanar as dificuldades que assolam o referido curso.

Assim, a pesquisa científica consolida-se como meio crucial para indagar as peculiaridades presentes no processo de formação docente, uma vez que abre grandes possibilidades na busca de soluções através das diversas metodologias, métodos e técnicas disponíveis. Dessa maneira, um passo inicial é entender que "Só se inicia uma pesquisa se existir uma pergunta, uma dúvida para a qual se quer buscar a resposta. Pesquisar, portanto, é buscar ou procurar resposta para alguma coisa" (GERHARDT; SILVEIRA, 2009, p. 12).

Partindo dessas premissas, serão apresentados os resultados da pesquisa que buscou explorar a percepção de sujeitos que estão no processo de formação docente no curso de Pedagogia, nas modalidades presencial e EAD, sendo, sobretudo, de instituições superiores diferentes. Visando enriquecer o processo de investigação, reflete acerca das considerações de importantes teóricos, cruzando as informações com vertentes teóricas da área. Entretanto, o intuito não é colher e mostrar dados inertes que expressem generalizações, mas sim, romper as limitações, confrontando e problematizando as experiências adquiridas, uma vez que compõem uma parte essencial para compreender a situação na qual se formam professores para educação infantil.

\section{Técnicas metodológicas e cenários de investigações}

Marconi e Lakatos (2003, p. 163) salientam que “Os métodos e as técnicas a serem empregados na pesquisa científica podem ser selecionados desde a proposição do problema, da formulação das hipóteses e da delimitação do universo ou da amostra". Diante disso, aplicou-se um questionário a 20 acadêmicos do curso de Pedagogia ofertado na modalidade presencial na Universidade Estadual de Goiás, eles são identificados, neste artigo, em ordem numérica, do $1^{\circ}$ ao $12^{\circ}$ com a sigla IF, significando informante, e realizou-se entrevista com dois acadêmicos do mesmo curso oferecido a distância na UNIGRAN, os quais serão denominados Entrevistados A e B. 
As instituições participantes da pesquisa estão localizadas em Campos Belos de Goiás e adotam formas diferentes em várias instâncias, uma ofertando a licenciatura em Pedagogia na modalidade presencial e a outra na EAD, apresentando configurações específicas de cada modo.

\section{Análise dos questionários aplicados no curso de Pedagogia da UEG - campus de}

\section{Campos Belos: experiências acadêmicas}

A análise dos dados coletados constitui-se como parte essencial para sanar as problemáticas encontradas, necessitando assumir posturas crítica e ativa. Não se deve apenas analisar e transcrever dados, e sim, interpretá-los, compreendendo as ideias expressadas em cada fala. Logo, de acordo com Gerhardt e Silveira (2009, p. 81), “A análise tem como objetivo organizar os dados de forma que fique possível o fornecimento de respostas para o problema proposto [...]”.

A interpretação será mediante apresentação das respostas, confrontando-as entre si, e ainda com importantes vertentes teóricas sobre o assunto. Além do que, ao discutir acerca de questões curriculares, estágio e outras de suma relevância e destaque, dentro do possível, ocorrerão debates de fundo com a grade curricular do curso investigado, estando disponível no site da instituição, que nesse caso será a da UEG - Campus de Campos Belos, visando de antemão obter uma análise mais profunda, embasada e compreensível. Também, quando necessário, serão usados gráficos para melhor apresentação dos resultados.

Sabe-se que, ao escolher determinado curso superior, o ingressante objetiva seguir uma carreira, logo deve saber que função estará assumindo: o estudante de medicina terá funções médicas, o de engenharia cargo de engenheiro e assim dentre outros exemplos, devendo estarem claras suas funções ao exercerem a profissão. Diante destas considerações, o primeiro questionamento voltou-se para saber qual a função do pedagogo. De maneira unânime, os informantes deixaram clara a grande amplitude da pedagogia e se referiram ao modo como funções voltadas à educação são de cunho do pedagogo, como destaca muito bem os IF $1^{\circ}, 2^{\circ}, 4^{\circ}$ e $5^{\circ}$ :

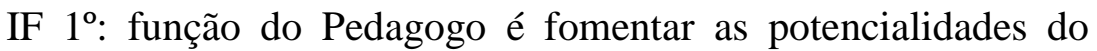
sujeito por meio do ensino e de modo algum ser "guardião", ou seja, babá destes cidadãos.

IF $2^{\circ}$ : Subsidiar o processo de ensino-aprendizagem em seus diversos contextos e em específico a docência possibilitar artifícios para a construção de um sujeito crítico, reflexivo e autônomo. 
IF 4: O pedagogo tem em sua principal função o de orientar e apontar os caminhos para a construção e consolidação do conhecimento.

IF 5': A função do pedagogo se faz presente nas áreas da educação e nos diversos contextos onde o pedagogo é apto a atuar. Acompanhando os planejamentos e o andamento da aprendizagem dos estudantes, favorecendo assim para a qualidade do ensino.

Apesar desta visão ampla relacionada à educação, outros se voltaram a uma função isolada de docente, trabalho na sala de aula, como diz o informante $3^{\circ}$ "Por mais que a pedagogia abrange várias áreas, nossa realidade é voltada à educação nos anos iniciais, onde temos a principal função ensinar conteúdos que pede a matriz curricular”.

Um fator importante a destacar é reconhecer que a função do pedagogo está intimamente ligada à identidade que ele constrói durante a sua formação, mas que esse aspecto logo seja esclarecido, pois deverá ter metas ao exercer uma função, então, como diz Libâneo (2005, p. 54), “A identidade profissional do pedagogo se reconhece, portanto, na identidade do campo de investigação e na sua atuação dentro da variedade de atividades voltadas para o educacional e para o educativo [...]". Entretanto, como as respostas deixaram claro, pedagogo relaciona-se com a educação em suas diversas instâncias, e como diz Libâneo:

[...] Desse modo, todos os profissionais que se ocupam de domínios e problemas da prática educativa em suas várias manifestações e modalidades e onde haja um caráter de intencionalidade são, genuinamente, pedagogos: pais, professores, supervisores de trabalho, agentes dos meios de comunicação, autores de livros, orientadores e guias de turismo, agentes de educação em movimentos sociais etc. [...] (LIBÂNEO, 2005, p. 55).

A segunda questão traz um assunto que muito se discute, o motivo do ingresso na licenciatura de Pedagogia, já que, se tratando de ser um profissional da educação infantil, o fator querer-fazer é mais do que vital. No entanto, através das informações, percebemse discursos um tanto longe do interesse na área, já que, dos 12 , somente o IF $8^{\circ}$ afirmou: "O desejo de ser professora me fez ingressar no curso de pedagogia". Além de mais dois informantes que expressaram interesse no campo educacional, o IF $10^{\circ}$ : "O sonho de criança de ensinar e aprender através de pesquisas e o convívio com outras pessoas”. E o IF 4": "Gosto da área da educação e o mercado de trabalho é mais amplo". Logo, os outros informantes voltaram-se à escolha do curso, motivados pelo acesso a um curso superior, 
como pode ser visto no IF $2^{\circ}$ : "A necessidade em ingressar no ensino superior, visto que não tinha condições financeiras em pagar um curso em outra região".

É visível que as escolhas expressam diversas situações, mas, independentemente das circunstâncias, ao ingressar e pensar em atuar na educação, estabelece-se um compromisso desde os estudos inicias do curso. E, como bem coloca Freire (1996, p. 103), “[...] O professor que não leve a sério sua formação, que não estude, que não se esforce para estar à altura de sua tarefa não tem força moral para coordenar as atividades de sua classe $[\ldots] . "$

Diante da percepção de Freire (1996), é nítida a necessidade de, ao entrar no curso de Pedagogia, dedicar-se na construção de conhecimentos, mas acima de tudo, aprender a gostar, uma vez que o IF $9^{\circ}$ afirmou: "Meu ingresso no curso de Pedagogia foi por falta de dinheiro para pagar um curso melhor". Visivelmente, ideais pragmáticos e alienados devem ser descontruídos, e o melhor é que durante a formação se consiga superar as ideias limitadas e ambíguas, pois, do contrário, não adiantará em nada esta dita formação superior.

Pelo exposto e diante da amplitude da Pedagogia, cabe se perguntar como é tratada a Educação Infantil, uma vez que, como destaca Trevisol, Maziero e Lopes (2011, p. 112), “[...] A profissão docente, como todas as outras, pressupõe formação profissional específica e exige daqueles que a escolhem exercê-la através da construção de conhecimentos e habilidades específicas [...]”. Essa é uma questão relacionada ao trabalho com crianças, para as quais o curso citado diz preparar profissionais. Nesse sentido, solicitou-se, no questionário, uma avaliação, em uma escala de 0 a 10, do quanto a licenciatura em Pedagogia prepara profissionalmente, com saberes específicos para a docência na educação infantil? No gráfico abaixo se representam as respostas:

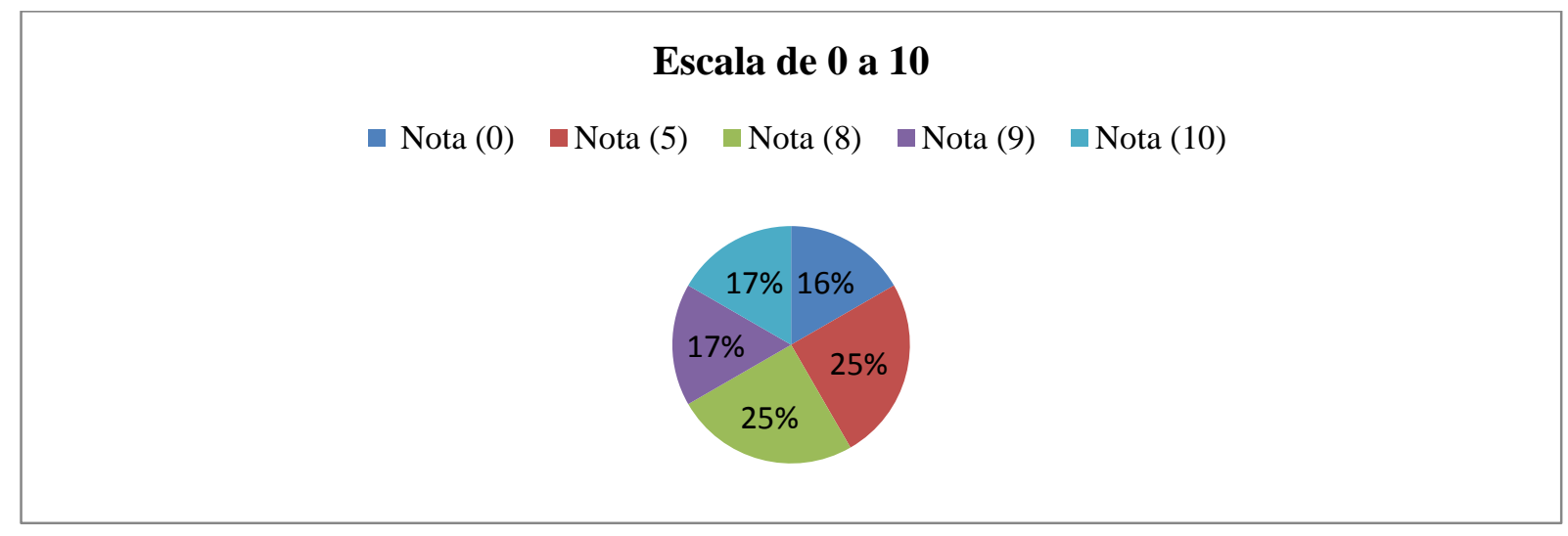

Como pode ser visto no gráfico, $17 \%$ dos participantes afirmaram uma falta de saberes específicos relacionados à educação infantil. Isso é muito preocupante, já que este MARGENS - Revista Interdisciplinar 
é um curso dito formador de docentes para o exercício no âmbito infantil. Dessa maneira, faz-se uma ligação à outra pergunta, a de número 6, sobre a contribuição ou não das disciplinas para a preparação do docente, em específico, voltado à educação infantil e, corroborando a situação anterior, 6 informantes responderam "pouco", seguido de 4 que expressaram-se com "razoavelmente", e apenas dois julgaram "muito". Através dessas afirmações, enfatizando acerca de disciplinas do curso, Leite ressalta:

Os programas de ensino das diferentes disciplinas dos cursos estão estruturados curricularmente e, de modo geral, vêem sendo trabalhados de forma desarticulada das demandas da prática e da realidade encontrada nas escolas, caracterizando-se por uma concepção burocrática e acrítica, baseada no modelo da racionalidade técnica [...] (LEITE, 2011, p. 38).

Diante das informações refletidas nas questões acima e em uma possível análise das disciplinas específicas sobre educação infantil, presentes na grade curricular da licenciatura em Pedagogia anual/semestral - 2009 da UEG - campus de Campos Belos, disponível no site da instituição, seriam encontradas um total de quatro, sendo elas: Propostas Curriculares e Metodológicas em Educação Infantil; Literatura Infantil; Atividades De Orientação - I Docência Na Educação Infantil I, respectiva ao Estágio Supervisionado Em Docência Na Educação Infantil I; e Atividades De Orientação Em Docência Na Educação Infantil II, direcionada ao Estágio Supervisionado Em Docência $\mathrm{Na}$ Educação Infantil I, apesar de que outras possuem uma abertura quanto a essa especificidade, já que podem se referir tanto à educação infantil, como às séries inicias do ensino fundamental, por exemplo, "História Social da Criança".

Montam-se logo inquietações acerca do caráter formativo de professores para mais de uma área em um só curso, pois, é clara a manifestação dos participantes quanto à necessidade da exploração dessa área específica. O que no entanto não elimina o caráter reflexivo e propiciador de leituras que a Pedagogia busca promover, além de ser apenas o início da aprendizagem do futuro professor, bem como expressa Trevisol, Maziero e Lopes:

O curso de Pedagogia é considerado o início da aprendizagem da docência, concebido como um espaço de leitura, discussões e reflexões acerca da educação. A aprendizagem docente se dá também na prática profissional, no contato com o aluno [...] (TREVISOL, MAZIERO E LOPES, 2011, p. 110).

Apoiando-se nas ideias dos teóricos supracitados é notável que não se forma professores somente com um aglomerado de disciplinas e conhecimentos específicos, e sim, necessariamente com a colaboração de professores em prática, devendo ser realizada 
uma conexão entre as práticas pedagógicas com crianças, em que a comunicação é vital, com a cooperação de docentes que estão atuando e, sobretudo, com os caminhos para se tornar um profissional. Logo não adiantará diversas disciplinas específicas da educação infantil sem que as mesmas sejam exploradas de maneira teórica e prática, bem como falar da alfabetização sem que vivencie o processo prático.

Pautada em uma perspectiva profunda das disciplinas da grade supracitada, acabase que as disciplinas trazem características de várias instâncias do campo educacional, entretanto quando a LDBEN 9394/96 destaca uma das finalidades do ensino superior, no inciso III do art. $43^{\circ}$, como sendo a de "incentivar o trabalho de pesquisa e investigação científica [...]" torna-se perceptível a universidade como detentora de promover a pesquisa para então, no caso da preparação docente, obter uma formação movida por meio do ato de pesquisar, de ler e produzir.

Neste contexto, na análise dos dados das questões 4 e 5, encaminha-se a compreensão do ponto de vista de professores pesquisadores e leitores e, ao mesmo tempo, do modo como ocorre o processo de aprendizagem da docência, sendo que na de número 5, ao se questionar quais metodologias a maioria dos professores tem utilizado predominantemente, 7 dos informantes concordaram em "Aulas expositivas, com participação dos estudantes", partindo ao quesito interação e discussão de saberes, como um fator benéfico. Entretanto, 3 confirmaram o uso de "trabalhos de grupo desenvolvidos em sala de aula", e 2 marcaram a opção "outra".

Sabe-se que a pesquisa é um fator decisivo na formação do professor, pois é um meio pelo qual se proporciona uma preparação que formam docentes pensantes. $\mathrm{Na}$ universidade, a maneira pela qual este aspecto é tratado, as formas como o acadêmico em pedagogia possui contato com a pesquisa no campo educacional, divergem opiniões, sendo que, como salienta Libâneo,

Sabe-se que são consideráveis as deficiências do professorado em relação a aprender a pensar, de modo que eles próprios necessitam dominar estratégias de pensar e de pensar sobre o próprio pensar. Tais questões levam as instituições formadoras a perguntas como: Como ajudar os professores a se apropriarem da produção de pesquisa sobre educação e ensino?[...] (LIBÂANEO, 2000, p. 86).

Embora seja evidente a relevância do pesquisar criticamente, os informantes, ao serem questionados sobre a contribuição da disciplina de metodologia científica para a realização de pesquisas nas diversas áreas do campo educacional, dividiram as respostas em três considerações, a maioria, sendo eles 6 informantes disse ser "Pouco", o IF. $2^{\circ}$ 
justificou "A falta de uma disciplina que aprofunde mais nesse campo" e o IF.12 "Pois, são bem superficiais", enquanto 4 classificaram "Razoavelmente" e apenas 2 "Muito", em que exclusivamente um justificou a escolha.

Pesquisar demanda também em ir a campo, para tanto teoria e prática aparecem como essenciais. Um assunto que há tempo provoca discussões, pois pensar em formação docente sem que sequer vivencie o seu futuro campo de educação não é uma ideia de qualidade. Veja-se que, ao ser solicitado aos participantes para em uma escala de 0 a 10 classificar se houve junção entre teoria e prática, obtiveram-se as respostas abaixo representadas:

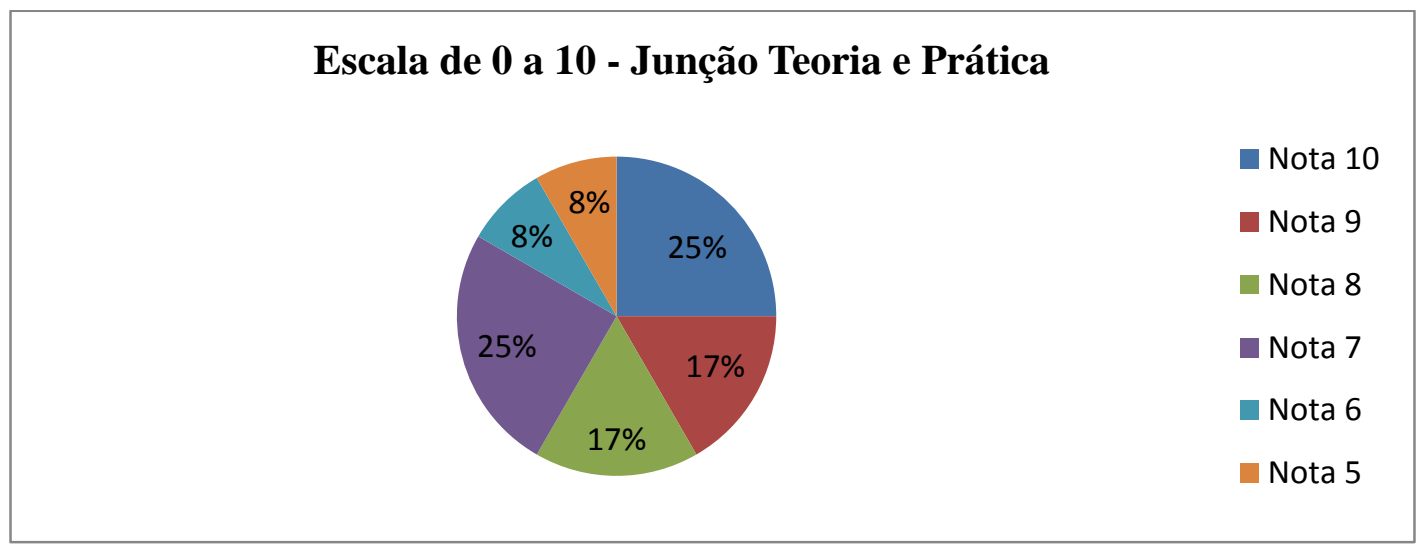

A partir da representação do gráfico percebe-se que houve uma grade fragmentação das escolhas, uma vez que a nota máxima e o valor sete obtiveram maior preferência. No entanto, vale destacar que somente um dos informantes, o que optou pelo 10, justificou de acordo com as características da questão, salientando que "Houve sim a junção entre a teoria e prática, pois diante dos estudos e pesquisas realizados em sala de aula, foi que colocamos em prática os conhecimentos adquiridos e sempre buscando aperfeiçoar" (IF. $5^{\circ}$ ). Entretanto, os demais relataram o motivo da opção, porém sem fazer a relação que a pergunta solicitava, a da teoria e da prática integrada nas disciplinas, como se percebe na fala do IF. $10^{\circ}$ : "Toda prática tem total ligação com a teoria, ela é o ponto norteador que nos leva a reflexão da prática em sala. Não há prática sem teoria”.

Ademais, os participantes expressaram a ideia de prática apenas no estágio supervisionado, pois como o IF. $2^{\circ}$ destaca "Somente no estágio que houve uma rápida oportunidade, necessita de aulas mais práticas." E também o IF. $12^{\circ}$ que resumidamente afirma "Somente no estágio". Situações estas que Libâneo aponta:

Atualmente, em boa parte dos cursos de licenciatura, a aproximação do futuro professor à realidade escolar acontece após ter passado pela formação "teórica" tanto na disciplina específica como nas disciplinas pedagógicas. O caminho deve ser 
outro. Desde o ingresso dos alunos no curso, é preciso integrar os conteúdos das disciplinas em situações da prática que coloquem problemas aos futuros professores e lhes possibilite experimentar soluções, com a ajuda da teoria. Isso significa ter a prática ao longo do curso [...] (LIBÂNEO, 2000, p. 95)

Percebe-se, na fala de Libâneo, a necessidade da articulação entre a teoria e a prática desde o início da formação do futuro professor. Para tanto, os participantes mostram uma visível obrigação de ações voltadas para este aspecto, ressaltando o quanto ainda se tem a evoluir, mas, inquestionavelmente, não apenas ver peculiaridades teóricas em prática, porém construir uma visão crítica e reflexiva acima de qualquer momento prático, já que como afirma Freire (1996, p. 24) “A reflexão crítica sobre a prática se torna uma exigência da relação Teoria/Prática sem a qual a teoria pode ir virando blábláblá e a prática, ativismo".

Todavia, essa pedida reflexão da teoria e prática demanda um acadêmico instigado pela criticidade, somando-se as contribuições teóricas e didático-pedagógicas, para que tenha a possibilidade de desenvolver um processo de ensino-aprendizagem pautado pelas indagações, eliminando as mazelas de um estudo mecânico e técnico. Perante o exposto, ao questionar os participantes se a pedagogia integra a criticidade ao papel do docente no contexto educacional infantil, obteve-se a seguinte afirmação:

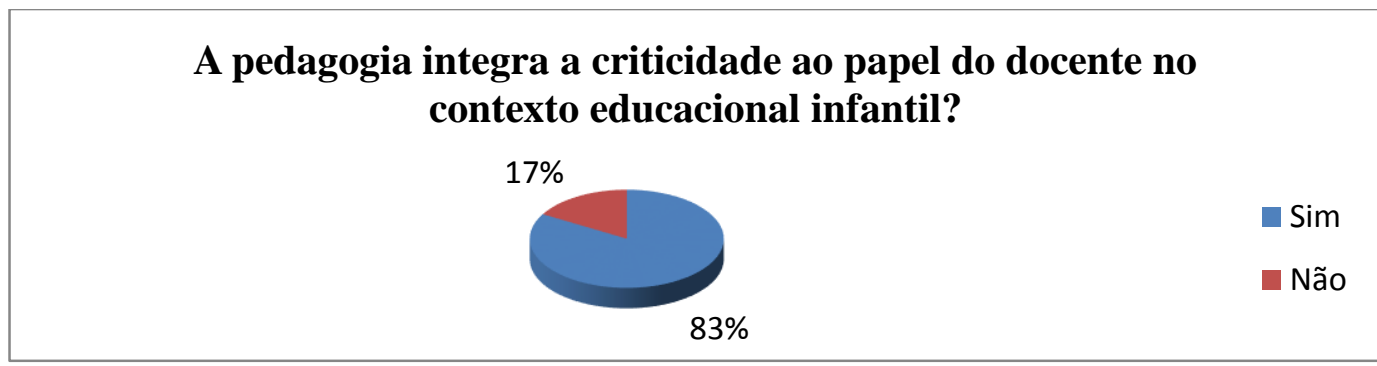

A confirmação de $83 \%$ dos informantes comprova o sentido epistemológico, propiciador de leituras e produções críticas do curso de Pedagogia, em que uns dos estopins para esse feito é o diálogo. Fato este confirmado através das informações dos participantes em outra questão que dividiu as respostas entre $50 \%$ ótimo e $50 \%$ bom, ao se questionar como avaliam o papel ou a importância do diálogo na produção de conhecimentos e saberes da carreira docente.

As respostas dos participantes reafirmaram a valorização do diálogo na construção de conhecimentos, uma vez que a formação docente propicia a assimilação de saberes específicos, ao ser realizada uma difusão de experiências e, sobretudo, relacionando-se à criticidade do estudante. Destarte o IF. $2^{\circ}$ afirma que "O diálogo é a base para a construção de conhecimentos", e o IF. $5^{\circ}$ complementa: 
IF. $5^{\circ}$ : Pois é necessário que tanto educador, quanto os discentes estejam em um processo de interação, capazes de se comunicar, expor ideias, argumentar sobre as necessidades do aluno, criar ambientes satisfatório e prazeroso, buscando as diretrizes pedagógicas, a melhoria e a qualidade do ensino ofertado aos estudantes.

Para fortalecer o elo entre conhecimentos teóricos e práticos e eliminar uma visão antagônica como muito se propaga, percebendo que o diálogo, criticidade e junção teoriaprática concretizam-se como pilares vitais na preparação da qualidade do professor para a educação infantil, pois de nada progredira uma vivência prática se acabar-se por reproduzir ambiguidades presente no cotidiano escolar, vale trazer o artigo $3^{\circ}$ da Resolução CNE/CP n ${ }^{\circ}$, de 15 de maio de 2006, que institui Diretrizes Nacionais para o Curso de Graduação em Pedagogia, enfatizando o debate acerca do estudante de Pedagogia:

O estudante de Pedagogia trabalhará com um repertório de informações e habilidades composto por pluralidade de conhecimentos teóricos e práticos, cuja consolidação será proporcionada no exercício da profissão, fundamentando-se em princípios de interdisciplinaridade, contextualização, democratização, pertinência e relevância social, ética e sensibilidade afetiva e estética. (CNE/CP, 2006)

É impossível negar as dificuldades que percorrem a formação docente do profissional em educação infantil. No entanto, não estão ligados apenas ao lado da preparação em si, na instituição formadora, pois muitas são as peculiaridades para se construir uma postura profissional. Todavia, em caráter de conclusão e partindo dessas considerações, ao pedir que os participantes apontassem um desafio presente na licenciatura em Pedagogia, visando em específico à área da infância e uma possível forma de superá-lo, houve uma grande divergência de opiniões, porém voltou-se para eixos de suma relevância como o estágio supervisionado, prática e grade curricular:

IF. $10^{\circ}$ : O maior desafio que se encontra ao meu ver é a prática que nos é oferecida através do estágio, que ainda não estamos preparados, e o tempo que nos é oferecido é limitado.

IF. $2^{\circ}$ : Disciplinas direcionadas ao ser professor na educação infantil, como ser? Dispor mais de práticas pedagógicas. Atualizações na grade do curso, contemplar disciplinas da educação básica.

IF. $12^{\circ}$ : Disciplinas voltadas para essa área.

IF. $3^{\circ}$ : Na minha opinião, o curso deverá oferecer um estágio maior e de preferência, remunerado, pois quem trabalha não consegue ter um grande rendimento.

IF. $8^{\circ}$ : A falta de atividade docente voltada para a prática. 
Diante das novas exigências educacionais para o exercício da profissão docente, requer-se uma formação sólida e de qualidade, bem como sustenta o informante $5^{\circ}$ "Acredito que um dos maiores problemas está ligado a falta de preparo dos educadores. Por isso, como forma de superar esse desafio é necessário a formação qualificada, logo Granville afirma:

[...] Formação supõe, necessariamente, uma política estruturada, que considere os desejos, as necessidades e o contexto desse profissional. Não basta identificar a formação do professor como problema, é necessário pensar e operacionalizar ações efetivas que solucionem a questão. [...] (GRANVILLE, 2007, p.167).

Em sua totalidade, os informantes contribuíram para entender parte de como ocorre o processo de formação do profissional para a educação infantil, mostrando inquietações existentes, bem como, pontos benéficos para uma preparação de qualidade, uma vez que possibilitaram dialogar suas experiências e, acima de tudo, exaltaram a necessidade de um processo formador reflexivo, que implica em rever modelos e apresentar constantemente atualizações e, sobretudo, mudanças.

\section{Entrevista com acadêmicos da EAD: peculiaridades do ensino a distância}

Sabe-se que a entrevista possibilita colher uma série de informações, no entanto, ser fiel ao transcrever o discurso dos participantes é aspecto vital. Logo, esperam-se contribuições proporcionadas através da participação de acadêmicos da EAD, aqui denominados Entrevistados A e B. Apesar de cada entrevista ter sido realizada separadamente ocorrerá um diálogo de fundo entre as significações representadas.

As perguntas das entrevistas buscaram entender aspectos inerentes a EAD enquanto modalidade formadora de docente, em específico do curso de Pedagogia, enfatizando características específicas de uma formação inicial em uma modalidade de grande ascensão. Sendo assim, inicialmente questionou-se o motivo da escolha por Pedagogia e, sobretudo, pela modalidade a distância, e as respostas se aproximaram ao interesse pela área da educação, como relataram os participantes, muito embora, tenham sido encontrados os seguintes motivos: "quanto a modalidade a distância foi por não conseguir aprovação no vestibular do presencial", entrevistado A (2016); e o entrevistado B (2016) assim justificou, "Escolhi fazer a distância, pois trabalho e quase não tenho tempo, essa foi a melhor forma que encontrei de acesso ao ensino superior".

É preciso evidenciar no discurso dos participantes uma escolha movida por aspectos além da dita identificação pela educação, já que é possível perceber o anseio ao acesso do ensino superior. Entretanto, adentrando as especificidades do ensino a 
distância, perguntou-se aos entrevistados como eles analisam as metodologias utilizadas pelos professores, visando o ensino mediado pelas tecnologias?

Falta mais atenção, quanto aos professores deixam muito a desejar, não trazem novas formas de ensino. (Entrevistado A, 2016)

As vezes os professores deixam a desejar pois precisaria mais de contanto entre professores e alunos. (Entrevistado B, 2016)

Entretanto, ao refletir sobre a metodologia em EAD, vários elementos devem ser elencados, uma vez que os textos estudados passam a ser centrais na formação. Nesse sentido, ao ser perguntado sobre o tipo de material didático predominantemente usado na sua formação, o entrevistado A (2016) afirmou "material impresso, que são livros com conteúdos de cada disciplina organizado pelo professor da mesma"; e se aproximando dessa mesma linha, porém, expresso de maneira sucinta, o entrevistado B (2016) disse "Livros e internet". Nessa perspectiva, Netto, Giraffa e Faria discorrem:

Em relação ao material didático, um curso de qualidade deve apresentar os materiais didáticos em formato web (disponíveis na Internet), impresso e em multimídia (CD e DVD). Essa variedade de formatos se justifica se levarmos em conta os diferentes tipos de aprendizagens e a heterogeneidade da realidade de cada aluno, considerando o país como um todo. (NETTO; GIRAFFA; FARIA, 2010, p. 111-112)

A partir das falas dos entrevistados é nítido o pouco diálogo entre docente e discente, fato este que se corrobora mais ainda nas próximas perguntas. Ao pedir que, em uma rápida análise do momento em que ingressou até a atual situação, os entrevistados avaliassem a interação entre acadêmicos e professores, assim relataram: é "Muito fraco, porque não há encontros presenciais, então vamos no polo só fazer as provas" (Entrevistado A, 2016) e “A interação entre professores e alunos não é muito viável, pois deveria ter aula presencial e mais contato com os professores" (Entrevistado B, 2016). Logo, uma das particularidades vitais para a construção do conhecimento é pouco explorada, o diálogo. Não é possível pensar o processo de ensino-aprendizagem fora de uma relação entre os sujeitos envolvidos, cujo eixo não seja o processo dialógico. É o que bem analisam Netto, Giraffa e Faria:

Num ambiente de Educação a Distância a aprendizagem não pode ser passiva, pois as interações são fundamentais aos processos de aprendizagem, tanto as interações entre aluno-aluno quanto aluno-professor. É por meio das interações que o processo de conhecimento se desenvolve colaborativamente (NETTO; GIRAFFA; FARIA, 2010, p.109-110). 
As informações acusam a falta de comunicação, apontada pelos informantes, como um grande desafio, já que mais à frente, ao se indagar quais desafios estão presentes na formação docente na educação a distância e como solucioná-los, enfatizou-se novamente a questão da interação, pois o entrevistado A (2016) argumentou que "Falta de diálogo ou seja, nos momentos que precisamos de uma explicação, então deixa muito a desejar"; e neste mesmo ponto de vista se constitui a fala do entrevistado B (2016) que disse: "Falta de diálogo com os alunos. A solução é ter mais contato e dar mais atenção para os alunos". Acerca das metodologias utilizadas na EAD, bem como dos aspectos inerentes a isso, Teperino et. al. discorre:

É importante compreender que a "arte de ensinar" dos professores em EAD não pode se basear em qualidades retóricas, como ocorre no ensino presencial. Na educação a distância, é preciso combinar funções do comunicar, do explicar e do orientar em seus textos didáticos, estruturando-os adequadamente, com vistas às necessidades cognitivas dos alunos. Passando, assim, da exposição dos conteúdos a serem ensinados para a disponibilização e iniciação de processos cognitivos de aprendizagem (TEPERINO et. al., 2006, p.85).

Sabe-se que a interação na EAD significa ir além da presencialidade e inclui as novas tecnologias, porém, os encontros presenciais estão fixados na legislação que regem a educação a distância. Ao perguntar aos participantes quais atividades são desenvolvidas nos encontros presenciais, se ocorrem mudanças em seus horários e datas previstos, ou qual a contribuição destes encontros para a sua qualificação como docente da Educação Infantil, obteve-se as seguintes respostas: "Não há encontros, só vamos no polo fazer a prova." (Entrevistado A, 2016); "Somente provas, sempre são provas, a contribuição é que tento buscar resultados e aprimorar cada vez mais" (Entrevistado B, 2016).

Em meio a um embaralhado de particularidades, a aprendizagem é medida muitas vezes apenas por questões em uma prova escrita, considerando reproduções de conteúdos como resultado de estudos, foi o que se constatou ao solicitar que os entrevistados descrevessem o processo de avaliação nas disciplinas, assim discorreram:

Ocorre através de atividades e provas, atividades essas com questões sobre o conteúdo e também pedindo produção de textos que são enviadas por um portfolio, e as provas vamos até o polo fazer, porém não acho muito viável porque falta interação do aluno e professor (Entrevistado A, 2016).

Os métodos de avaliação deveriam ser mais amplos a respeito das atividades enviadas via portfolio, pois acabam em certos casos por limitar o processo de avaliar (Entrevistado B, 2016). 
Através das respostas dos entrevistados é possível perceber certa mecanização quanto ao processo de ensino-aprendizagem, já que ele acaba por se reduzir em responder atividades e provas. Os participantes expressaram a necessidade de novos métodos de se avaliar, pois se percebe que a aprendizagem não está sendo entendida como um conjunto, mas como momentos isolados. Todavia, em torno da avaliação Vallin comenta:

Mesmo em alguns cursos de EAD com propostas mais progressistas e libertadoras, é comum que, na hora da avaliação da aprendizagem, se recaia em práticas conservadoras. A avaliação deve fazer parte do processo pedagógico, é um importante instrumento, e não deve ser vista de forma isolada (Vallin, 2014, p. 51).

Ainda neste âmbito do diálogo, percebendo a importância da comunicação na EAD, sendo que o não contato físico na hora de sanar uma dúvida ou algo assim requer maior atenção, questionou-se aos informantes como são buscadas as soluções quando eles se deparam com dúvidas em relação aos conteúdos e trabalhos. Forma obtidas as seguintes respostas:

Procurando ajuda com os colegas e professores, mas na maioria das vezes procuro alunos de outras instituições, como os da UEG na modalidade presencial para me ajudar (Entrevistado A, 2016). Pesquisa na internet, amigos e também o acesso a plataforma no fórum, arquivo e quadro de avisos, mas grande ajuda é de alunos do mesmo curso em outras instituições (Entrevistado B, 2016).

Nesta área de conteúdos e, sobretudo, acerca das disciplinas do curso em questão, realizaram-se duas perguntas cujo teor de cada uma tratou das especificidades da educação infantil, buscando saber se as disciplinas traziam os saberes exclusivos desta área e os aspectos necessários para trabalhar com crianças. Os entrevistados informaram a presença desta especificidade nos estudos, porém, deixando clara a necessidade de união com a prática, como pode ser observado em parte da fala do entrevistado A (2016) “[...] Mas deveria abordar mais aspectos práticos da educação infantil, fazer maior ligação com a escola”. E também quando diz o entrevistado B (2016) “[...] a prática deveria ser mais explorada, assim me sentiria mais preparada, pois acaba por ficar muito nas leituras".

É visto nas respostas a preocupação dos entrevistados com a prática em si, pois eles almejam uma ligação maior com a escola. Nessa mesma linha de pensamento Nóvoa (2009) traz grandes contribuições, uma vez que aponta para a necessidade de maior aproximação entre universidade e o futuro campo de atuação, como pode ser observado em seu artigo intitulado "Para uma formação de professores construída dentro da profissão", no qual Nóvoa sustenta "A formação de professores deve passar para «dentro» 
da profissão, isto é, deve basear-se na aquisição de uma cultura profissional, concedendo aos professores mais experientes um papel central na formação dos mais jovens" (NÓVOA, 2009, p. 36).

Logo, ao perguntar aos entrevistados se o curso na modalidade EAD consegue promover a junção de teoria e prática e se os conteúdos das disciplinas são integrados em momentos práticos, questionamentos estes já bem explorados na pergunta anterior, os informantes afirmaram que "Em uma escala de 0 a 10 daria a nota 5, pois somente tem o estágio como prática, pois as disciplinas só trabalham atividades teóricas" (Entrevistado A, 2013); e, nesta mesma perspectiva, o entrevistado B relatou "Em relação as disciplinas acabam por isolar-se a estudos teóricos, já que o momento de grande prática é apenas o estágio, sendo este bem rápido".

Diante destas considerações é visível a fragilidade da junção teoria e prática, uma vez que os entrevistados não expressam visão dicotômica, mas sim, a falta de contato com seu futuro campo de atuação. Fator este o qual Nóvoa (2009, p. 32) acredita que "A formação de professores deve assumir uma forte componente práxica, centrada na aprendizagem dos alunos e no estudo de casos concretos, tendo como referência o trabalho escolar". E complementa dizendo,

Mas a verdade é que não houve uma reflexão que permitisse transformar a prática em conhecimento. E a formação de professores continuou a ser dominada mais por referências externas do que por referências internas ao trabalho docente. Impõe-se inverter esta longa tradição, e instituir as práticas profissionais como lugar de reflexão e de formação. (Nóvoa, 2009, p. 33).

A partir da fala do autor é notória a obrigação em quebrar paradigmas fixados historicamente e trazer a formação docente para dentro do seu campo de atuação. Fato esse desejado pelos sujeitos em formação, pois ao questionar se o seu curso oferece possibilidades para a construção da criticidade no exercício da docência na educação infantil, obteve-se as seguintes falas:

Sim. Apesar da falta de diálogo estamos sempre lendo textos, e assim nós conhecemos várias vertentes teóricas e obtendo uma bagagem teórico-crítica (Entrevistado A, 2016).

Sim. Ele oferece uma grande variedade de leituras, revisando a formação e buscando fortalecer ou promover processos de mudanças (Entrevistado B, 2016).

É diante da construção da criticidade que se baseia outra pergunta referente ao papel do acadêmico da EAD na sua formação profissional, pois é de suma importância se reconhecer como sujeito comprometido por suas qualificações e, ao invés de ser imóvel, MARGENS - Revista Interdisciplinar 
buscar a construção de conhecimentos, estando ativo e crítico. Sobre essa questão os entrevistados relataram:

Autodisciplina para regular as atividades feitas, pois sou responsável pelo ensino e aprendizagem (Entrevistado A, 2016).

O meu papel é ser ativo e reflexivo, construir um processo de aprendizagem pautado pela leitura (Entrevistado B, 2016).

Todavia, os entrevistados expressaram experiências e representações no que se refere ao preparo profissional para atuação na área educacional através da EAD. Por fim, ao ser indagado que pontos positivos e negativos os entrevistados destacavam no ensino online da formação docente para educação infantil, de maneira sucinta mencionaram:

Positivo é a flexibilização que a modalidade proporciona. Negativo é a questão que não tem nenhum dia presencial, os alunos só vão ao polo fazer as provas (Entrevistado A, 2016).

Pontos negativos: Deveriam ter aulas presencial com alunos. Pontos positivos: Tem ótimo material para ser estudado (Entrevistado B, 2016).

Em suma, é nítido que as informações dos entrevistados contribuem essencialmente para compreender especificidades da formação de professores a distância, porém é visto que não se pode generalizar, já que se trata de reproduções de um cotidiano acadêmico, no qual se podem diferenciar outros sujeitos.

\section{Considerações Finais}

São notórias as mazelas representadas por meio das diversas falas, causando preocupação e solicitando olhares mais severos quanto à forma que se preparam profissionais para a educação infantil. Mas, além do ato de se formar com todos os saberes necessários, o ponto inicial é compreender o seu papel para não persistir com ideias alienadas do que é ser professor, já que, como afirma Paula (2015, p.7), ao se referir a atividades de quem cursa Pedagogia “[...] isto não faz do pedagogo um semideus [...], servindo estas palavras para o professor da educação infantil, aquele que deve proporcionar uma formação integral, que não deve assumir todas responsabilidades educativas de uma criança e, muito menos, realizar milagres.

Diante do exposto, é visível que são urgentes as transformações nos âmbitos que ocorrem a formação docente. Na EAD, nota-se a necessidade em reduzir a distância, até porque ainda se fala em formação humana para humanos. No que se refere à modalidade presencial, é mais do que preciso combater os embates do arcaico, buscando inovar frente à grande presença do tradicionalismo. 
Percebe-se a necessária busca cotidiana de uma nova pedagogia, de ressignificação do curso de grande valor na preparação do professor, até porque se fala em preparar aquele que prepara a sociedade.

\section{Referências}

BRASIL. Conselho Nacional de Educação. Resolução CNE/CP n. 1, de 15 de maio de 2006. Institui Diretrizes Curriculares Nacionais para o Curso de Graduação em Pedagogia, licenciatura. 2006, Diário Oficial da União, Brasília, 16 de maio de 2006, Seção 1, p. 11. Disponível em: http://portal.mec.gov.br/cne/arquivos/pdf/rcp01_06.pdf. Acesso em: 18 de agosto de 2016.

BRASIL. Ministério da Educação e do Desporto. Secretaria de Educação Fundamental. Lei de Diretrizes e Bases da Educação Nacional, LDB. Lei n. 9394,20 de dezembro de 1996 - 8 ed. Brasília: MEC/SEF, 1996.

ENTREVISTADO A. [set. 2016]. Entrevistador: Maike Soares de Souza. Distrito Prata, Monte Alegre - GO, 2016. 1 arquivo, mp3.

ENTREVISTADO B. [set. 2016]. Entrevistador: Maike Soares de Souza. Distrito Prata, Monte Alegre - GO, 2016. 1 arquivo, mp3.

FREIRE, Paulo. Pedagogia da Autonomia: saberes necessários à pratica educativa. 24 ed. São Paulo: Paz e Terra, 1996, 165p. (Coleção Leitura).

GERHARDT, Tatiana Engel; SILVEIRA, Denise Tolfo (Org). Métodos de pesquisa. Porto Alegre: Editora da UFRGS, 2009.

GRANVILle, M. A. Teorias e Práticas na Formação de Professores. Papirus, 2007.

LEITE, Yoshie Ussami Ferrari. O lugar das práticas pedagógicas na formação inicial de professores. São Paulo: Cultura Acadêmica, 2011.

LIBÂNEO, José Carlos. Adeus professor, adeus professora? Novas exigências educacionais e profissão docente. 4 ed. - São Paulo: Cortez, 2000. (Coleção Questões da Nossa Época; v. 67).

LIBÂNEO, José Carlos. Pedagogia e pedagogos, para quê? 8 ed. - São Paulo, Cortez, 2005.

LOPES, A. R. L. V; MAZIERO, M. P.; TREVISOL, M. T. C.; Contribuição do Programa de Alfabetização Regional (PAR) para a Formação de Futuros Pedagogos: Análise de uma Experiência. In: LOPES, A. R. L. V; TREVISOL, M. T. C; PEIREIRA, P. S. (Org.). Formação de Professores em Diferentes Espaços e Contextos. Campo Grande, MS: Ed. UFMS, 2011, p. 103-126.

MARCONI, Marina Andrade; LAKATOS, Eva Maria. Fundamentos de metodologia científica. 5. ed. - São Paulo : Atlas 2003. 
NETTO, Carla; GIRAFFA, Lucia M. M; FARIA, Elaine T. Graduações a distância e o desafio da qualidade [recurso eletrônico]. Porto Alegre: EDIPUCRS, 2010.

NÓVOA, António. Para uma formação de professores construída dentro da profissão. In:___ Professores: Imagens do futuro presente. Lisboa |Portugal: EDUCA, 2009. Cap. 2.

PAULA, Geraldo Magela. Ética Profissional do Pedagogo: Escrita ou Vivida. 2015. Disponível em: https://gmagela.files.wordpress.com/2014/12/etica-pedagogo-numerado1.pdf. Acesso em: 10 de out. 2016.

TEPERINO, A.S. et al. Educação a Distância em Organizações Públicas: mesaredonda de pesquisa-ação. Brasília: ENAP, 2006.

VAllin, Celso. Educação a Distância e Paulo Freire. Associação Brasileira de Educação a Distância, RBAAD, Volume 13 - 2014. Disponível em: 〈http://www.abed.org.br/revistacientifica/_Brazilian/2014/02_ead_paulo_freire_pt.pdf > Acesso em: 13 de julho de 2016. 